\title{
Proliferation zones in the salmon telencephalon and evidence for environmental influence on proliferation rate
}

\author{
Sean C. Lema ， Mark J. Hodges , Michael P. Marchetti , Gabrielle A. Nevitt
}

\begin{abstract}
Cell proliferation occurs in the brain of fish throughout life. This mitotic activity contributes new neurons to some brain subdivisions, suggesting potential for plasticity in neural development. Recently we found that the telencephalon in salmonids (salmon, trout) is significantly reduced in fish reared in hatcheries compared to wild fish, and that these differences resulted in part from rearing conditions. Here, we describe localized areas of cell proliferation in the telencephalon of juvenile coho salmon (Oncorhynchus kisutch) and begin to explore whether mitotic activity in these areas is sensitive to environmental conditions. Using the 5-bromo-2'-deoxyuridine (BrdU) cell birthdating technique, we localized proliferating cells in the telencephalon to three distinct zones (proliferation zones 1a, 1b, and 2). We measured the volumes of these zones and showed that they grew at different rates relative to body size. We also found that variation in environmental rearing conditions altered the density of BrdU-labeled cells in proliferation zone 2, but not in zones 1a or 1b. However, this change in mitotic activity did not generate a difference in telencephalon size. These results suggest that environmental conditions, and associated changes in swimming activity or social structure, may influence rates of cell proliferation in the fish forebrain.
\end{abstract}

Keywords: Forebrain; Neurogenesis; Brain size; Brain morphology; Plasticity; Fish; Enrichment; Hatchery

\section{Introduction}

Brain structure and function can be dramatically affected by the environmental conditions that an animal experiences during development (for reviews, see Mohammed et al., 2002; van Praag et al., 2000). For instance, in rats, differences in the laboratory housing environment can induce significant changes in the dimensions of the cerebrum (Walsh et al., 1971, 1973), as well as changes in brain weight (Bennett et al., 1969; Rosenzweig and Bennett, 1969). More recently, enrichment of the rearing environment has also been linked to changes in the rate of cell proliferation and neuron survival in the brain of adult mice rodents (Kempermann et al., 1997; van Praag et al., 1999, 2000).

While most work has focused on laboratory rodents, the generation of new cells in the fish brain far exceeds that of the mammalian systems that have been studied (Zupanc, 2001a). For example, in adult weakly electric fish Apteronotus leptorhynchus, it has been estimated that, on average, $0.2 \%$ of the cells in the brain are in S-phase during any $2 \mathrm{~h}$ period (Zupanc, 2001b). Areas of cell proliferation have also been identified in several brain regions in adult stickleback (Gasterosteus aculeatus; Ekström et al., 2001) and sea bream (Sparus aurata; Zikopoulos et al., 2000). Some of these newly divided cells have been shown to differentiate into neurons in the olfactory bulb and cerebellum (Byrd and Brunjes, 2001; Zupanc, 2001b), and new neurons recruited from these proliferation zones may contribute to the regenerative ability documented in the central nervous system of fishes (Stuermer et al., 1992; 
Sullivan et al., 1997). Such elevated levels of proliferative activity may thus mediate life-long brain growth in fish (e.g., Birse et al., 1980; Mueller and Wullimann, 2002), as well as provide for plasticity in how fish brains develop and respond to environmental variability.

Recent evidence from captively propagated salmonids (trout, salmon) suggests that environmental influences may alter brain phenotype in fish reared in hatcheries (Marchetti and Nevitt, 2003; Kihslinger et al., 2003). Initial studies in rainbow trout (Oncorhynchus mykiss) showed that the telencephalon and other brain regions are significantly reduced in fish reared in hatcheries compared to those reared in the wild (Marchetti and Nevitt, 2003). It is not known, however, whether such differences in gross brain morphology result from artificial selection in hatcheries or can develop in an individual's lifetime. In subsequent studies with genetically similar strains of Chinook salmon (Oncorhynchus tshawytscha) reared both in hatcheries and in the wild, we have shown that differences in the volume of the olfactory bulb and telencephalon can develop within one year (Kihslinger et al., 2003). These findings suggest that the conditions that salmonids experience during development can have profound effects on neural phenotype.

Here we begin to explore the mechanisms by which environmental conditions alter brain size by localizing zones of cell proliferation in the salmon telencephalon. Our aim was to identify areas of proliferation that may be responsive to environmental conditions. Given that differences in telencephalon size were noted in previous studies comparing hatchery and wild-reared fish (Marchetti and Nevitt, 2003; Kihslinger et al., 2003), the telencephalon seemed an obvious place to look for areas of proliferation that might be sensitive to environment. This approach is similar to that applied in mammalian systems, where numerous studies have explored how environmental enrichment affects the rate of neurogenesis in the dentate gyrus of the hippocampus (i.e., Kempermann et al., 1997; van Praag et al., 2000). In this preliminary study, we used the established 5-bromo-2' deoxyuridine (BrdU) immunocytochemical cell birth-dating technique to localize zones of mitotic activity in the salmon telencephalon. We then asked how the size of these proliferation zones changes with growth of the fish. Lastly, we measured the density of BrdU-labeled cells in these zones and quantified the volume of the telencephalon to ask whether differences in rearing environment may be linked to differences in rates of proliferation or to changes in telencephalon size.

\section{Materials and methods}

\subsection{Animals}

Fertilized coho salmon (Oncorhynchus kisutch) eggs were obtained from the Iron Gate Fish Hatchery located on the Klamath River, California, USA. Eggs hatched in standard flow-through rearing trays in January 2000, and juvenile salmon parr were reared at the Center for Aquaculture and Aquatic Biology facility of the University of California, Davis. Once the yolk sac was absorbed, fry were moved to circular rearing tanks $(1.2 \mathrm{~m}$ diameter, $380 \mathrm{~L}$ capacity). On March 20th, 2000, fish were transferred to rearing treatment tanks and maintained there until sacrifice on July 25th, 2000. Fish were exposed to ambient photoperiod both prior and during the experiment. All procedures were approved by the Animal Care and Use Committee (Protocol \# 8482) of the University of California, Davis.

\subsection{Rearing treatment tanks}

Salmon parr were reared in two treatments that differed in habitat structure. The 'simple' (control) treatment lacked physical structure but had greater spatial variation in water flow velocity, while the 'structurally complex' (experimental) treatment was augmented with physical structures (i.e., cinder blocks, gravel), but had a more uniform hydrodynamic environment. For both treatments, salmon parr (40 fish per tank) were reared in $1.2 \mathrm{~m}$ diameter, circular flowthrough tanks. Water was provided from an on-site aquifer, chilled to $11 \pm 1{ }^{\circ} \mathrm{C}$, and entered the tanks at $15 \pm 1 \mathrm{~L} / \mathrm{min}$. Fish in both treatments were fed ad libitum.

For the 'simple' treatment, water entered through a spray bar (21.6 cm long, $1.27 \mathrm{~cm}$ diameter), circled the tank, and exited through a central drain. Spatial variation in the hydrodynamic environment was quantified by measuring water velocity with a flow meter (Flo-Mate ${ }^{\mathrm{TM}}$ Model 2000, Marsh-McBirney Inc., Federick, MD) at $2 / 3$ water depth $(\sim 10 \mathrm{~cm}$ from the bottom) in the center of fourteen $30 \mathrm{~cm}$ squares that comprised a grid over the bottom of the tank. Mean water velocity for the simple treatment tanks was 0.08 $\mathrm{m} / \mathrm{s}$ with a variance of $0.002(\mathrm{~m} / \mathrm{s})^{2}$. The average water depth was $30 \mathrm{~cm}$.

For the structurally complex treatment, the bottom of each tank was covered with gravel, and concrete cinder blocks (1 small, $19.1 \times 19.1 \times 19.1 \mathrm{~cm}$ cinder block, and 5 large, $39.4 \times 19.1 \times 19.1 \mathrm{~cm}$ cinder blocks in each tank in the same positions) were added for structure. Water entered the tanks through an elongated spray bar $(41.9 \mathrm{~cm}$ long $\times 1.27 \mathrm{~cm}$ diameter) directed toward the center of each tank. Water thus flowed across the tank, eventually exiting through a large drainpipe $(71.1 \mathrm{~cm}$ long $\times 5.08 \mathrm{~cm}$ diameter) parallel but on the opposite side of the tank as the spray bar. Mean water velocity for the structurally complex tanks was only $0.01 \mathrm{~m} / \mathrm{s}$ with a variance of $0.0001(\mathrm{~m} / \mathrm{s})^{2}$. Average water depth was $\sim 58 \mathrm{~cm}$ due to the added structure.

\subsection{BrdU immunocytochemistry}

Salmon parr (approximately 6 months after hatching) were anesthetized (MS-222 immersion, 1:1000, Crescent Research Chemicals), weighed and measured, and given a single intraperitoneal injection of $\mathrm{BrdU}(40 \mu \mathrm{L} / \mathrm{g}$ body wt of 
a $10 \mathrm{mg} \mathrm{BrdU} / 1 \mathrm{~mL} 0.9 \% \mathrm{NaCl}$ solution; Sigma). BrdU is incorporated into replicating DNA, and the systemic application of BrdU is a well-established technique for labeling mitotically active cells in a variety of taxa including fish (e.g., Zupanc and Horschke, 1995; Ekström et al., 2001; Lema and Nevitt, 2004a). Injected fish were fin-clipped for individual identification, and maintained together in a chilled $\left(\sim 11{ }^{\circ} \mathrm{C}\right)$, aerated tank until sacrifice. After a survival time of 13-14 h (no difference between treatments, $t$ test, $d f=5, t=0.244, P=0.8172)$, BrdU-injected fish were again deeply anesthetized (MS-222) and perfused by intracardial injection of chilled heparinized phosphate-buffered saline (PBS, $0.1 \mathrm{M}$ ) followed by Bouin's fixative. Brains were then dissected and postfixed in Bouin's for $12 \mathrm{~h}$. Tissue was dehydrated in a graded ethanol series, cleared in toluene, and embedded in paraffin.

After serial sectioning $(16 \mu \mathrm{m})$ and mounting, tissue sections were deparaffinized and rehydrated. Chromatin was precipitated with $2 \mathrm{~N} \mathrm{HCl}$ (30 min), followed by quenching endogenous peroxidase activity with $3 \% \mathrm{H}_{2} \mathrm{O}_{2}(15 \mathrm{~min})$. Tissue was rinsed between each step with PBS-D (PBS containing $1 \%$ dimethylsulfoxide; Sigma). After a $2 \mathrm{~h}$ blocking reaction with normal horse serum, sections were incubated overnight at $4{ }^{\circ} \mathrm{C}$ with primary anti-BrdU antibody solution (1:100 PBS-D dilution; Sigma). Antibody binding was visualized by incubation with a biotinylated horse antimouse IgG, avidin-biotin-peroxidase complex (mouse IgG $\mathrm{ABC}$ Kit; Vector Laboratories), and diaminobenzidine (DAB) with nickel enhancement. Sections were then rinsed twice in PBS, counterstained with cresyl violet, dehydrated in a graded ethanol series, and cleared in xylene before being coverslipped with Cytoseal 60 (Stephens Scientific). Staining controls where primary antibody was preincubated in BrdU prevented all immunohistochemical staining.

\subsection{Quantification of BrdU-ir cell density and telencepha- lon volume}

BrdU-ir cell counts and telencephalon volumes were determined using computer-aided analysis (AxioVision software, Zeiss, Oberkochen, Germany) of images captured via digital camera (Axiocam, Zeiss) attached to an Axioskop microscope (Zeiss). To quantify numbers of proliferating cells, we counted all BrdU-labeled cells in alternate sections every $32 \mu \mathrm{m}$ throughout the telencephalon. We also quantified the size of the proliferation zones. The volume of these zones was calculated by integrating the crosssectional area of the proliferation zones across the distance between sections (basic estimator of morphometric volume; Rosen and Harry, 1990; Uylings et al., 1986), and boundaries of proliferation zones were delineated by the extent of BrdUlabeled cells.

For each fish, we determined the volume of the telencephalon by tracing the cross-sectional area of the telencephalon in alternate sections every $32 \mu \mathrm{m}$. We defined the telencephalon as extending from the terminus of the internal cellular layer (ICL) of the olfactory bulb caudally to the end of the area dorsalis telencephali. The entopeduncular nucleus (but not the preoptic area) was included in our measurement of telencephalon volume. Telencephalon volume was calculated by integrating the cross-sectional area of the telencephalon across the distance between sections (Rosen and Harry, 1990; Uylings et al., 1986). Our description of telencephalic neuroanatomy follows the nomenclature described by Northcutt and Davis (1983).

\subsection{Statistical analyses}

Growth rate of each of the three proliferation zones was examined using the regression of proliferation zone volume against body mass. As we found no differences between treatments in the volume of proliferation zones $1 \mathrm{a}, 1 \mathrm{~b}$ or 2 , we combined treatments for this analysis. To determine whether the slopes of proliferation zone volume regressed against body mass differed among the zones, we used an analysis of covariance (ANCOVA) followed by Tukey tests for multiple pairwise comparisons among slopes (Zar, 1996). We then examined how rearing environment affected cell proliferation by using ANCOVA models, first with proliferation zone volume as a covariate and then with body mass as covariate, to compare the density of BrdU-labeled cells in each of the proliferation zones (1a, 1b, and 2).

Body mass and length were compared between treatments using Student's $t$ tests. Telencephalon volume was compared between treatments using an ANCOVA with body mass as a covariate. Statistical analyses were calculated using JMP 4.0.2 software (SAS Institute, Inc.), and all statistical tests that we performed were two-tailed.

\section{Results}

\subsection{Location of BrdU-labeled cells in the salmon forebrain}

BrdU-labeled cells were easily identified by a black precipitate indicative of the diaminobenzidine reaction product with nickel enhancement (Fig. 1). In general, BrdU-labeled cells were localized to three distinct regions of the telencephalon. These regions correspond to the three telencephalic proliferation zones (1a, 1b, and 2) located in or beside ventricular ependyma. These three zones have been described previously in other fishes using autoradiographic detection of ${ }^{3} \mathrm{H}$-thymidine and immunocytochemistry to proliferating cell nuclear antigen (PCNA) and BrdU (Ekström et al., 2001; Zikopoulos et al., 2000; Zupanc and Horschke, 1995; for review, see Zupanc, 2001b). As shown in Fig. 1, proliferation zone 1a (PZ 1a) comprises a thin zone of about one cell layer thickness that runs along the dorsal edge of the dorsal telencephalon. Proliferating cells that labeled positive for BrdU in zone 1a were scattered along the ventricular edge of the dorsal telencephalon. Proliferation zone 1b (PZ 1b) begins at the posterior boundary of the 

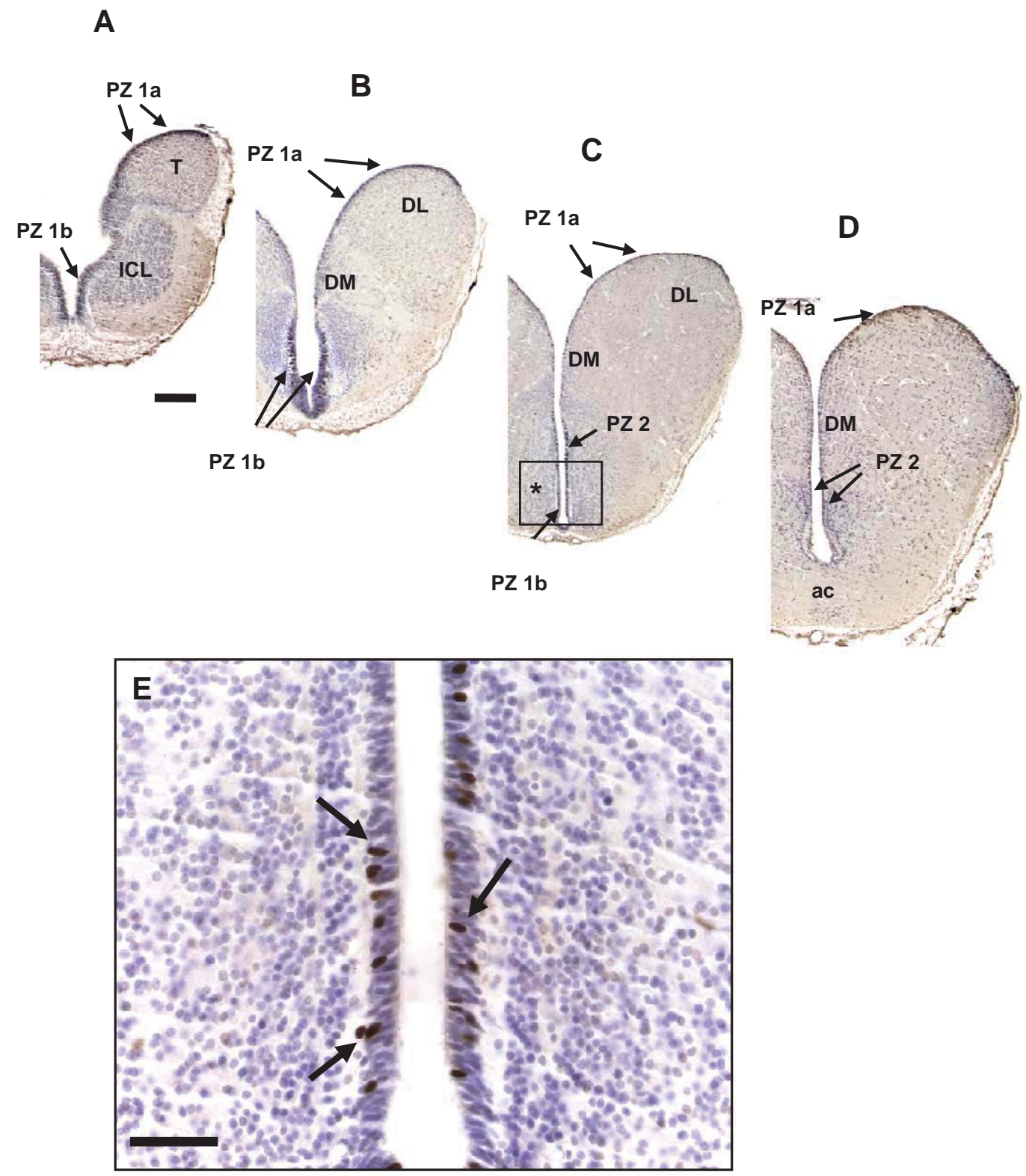

Fig. 1. (A-D) BrdU-labeled cells localized to three proliferation zones (PZs) termed 1a, 1b, and 2 in the telencephalon of coho salmon. Scale bar for A-D shown in A. (E) Magnified view of box (indicated by asterisk) in C, showing BrdU-labeled cells in PZ 1b. Abbreviations: T, telencephalon; ICL, internal cellular layer; DM, dorsal medial of telencephalon; DL, dorsal lateral of telencephalon; ac, anterior commissure. Scale bars: A-D, $200 \mu \mathrm{m}$; E, $50 \mu \mathrm{m}$.

internal cellular layer (ICL) of the olfactory bulb and continues caudally through the area ventralis telencephali (V). Proliferation zone 2 (PZ 2) begins at the rostral edge of the dorsal nucleus of the area ventralis telencephali and continues caudally to the anterior commissure (ac).

Proliferation zone volume showed a significant positive relationship with body mass for zone 1a $\left(r^{2}=0.7747\right.$, $\left.F_{1,5}=17.2000, P=0.0089\right)$ and zone $1 \mathrm{~b}\left(r^{2}=0.8768\right.$, $\left.F_{1,5}=35.5872, P=0.0019\right)$, but not for proliferation zone $2\left(r^{2}=0.4975, F_{1,5}=4.9505, P=0.0766\right)$. Comparing the allometric changes in the volume of each zone indicates a difference in rate of growth among the three proliferation zones (Fig. 2; $F_{2,15}=48.8558, P<0.0001$ ). Further analysis by multiple pairwise comparisons showed that each of the three proliferation zones grew at different rates (Tukey tests; zone 1a vs. zone $1 \mathrm{~b}, q=12.3658, P<0.001$; zone $1 \mathrm{a}$ vs. zone $2, q=10.2983, P \leq 0.001$; zone $1 \mathrm{~b}$ vs. zone 2 , $q=5.1157,0.005<P<0.01)$.

\subsection{Density of BrdU-labeled cells was influenced by rearing conditions}

The location of these telencephalon proliferation zones was similar among individuals from the simple and complex rearing treatments. However, the number of BrdU-labeled cells in proliferation zone 2 was higher in fish from the simple environment $(N=4)$ than from the structurally complex treatment $(N=3)$ (Fig. 3; ANCOVA, treatment effect, 


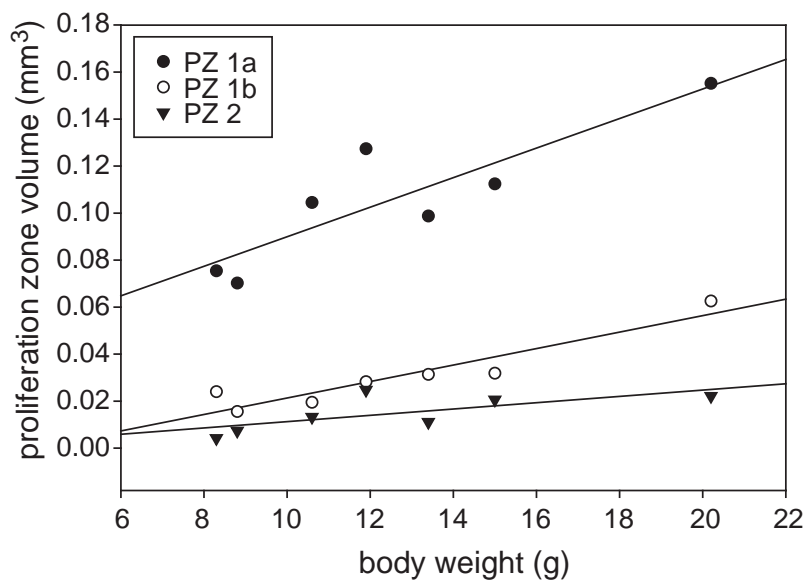

Fig. 2. The three telencephalic proliferation zones (PZ) 1a, 1b, and 2 grew at different rates $\left(F_{2,15}=48.8558, P<0.0001\right)$. As there was no difference between rearing treatments in the volume of any of the three proliferation zones, fish from both treatments were combined for analysis.

$F_{1,3}=15.4208, P=0.0294 ;$ PZ 2 volume effect, $F_{1,3}=60.5140, P=0.0044$; interaction $\mathrm{b} / \mathrm{w}$ treatment and PZ 2 volume, $\left.F_{1,3}=1.1053, P=0.3703\right)$. This difference represented an increase in the density of BrdU-labeled cells since there was no difference in PZ 2 volume among treatments when considering variation in body size (treatment effect, $F_{1,3}=3.7405, P=0.1486$; body wt effect, $F_{1,3}=1.5358, P=0.3034$; interaction $\mathrm{b} / \mathrm{w}$ treatment and body wt, $F_{1,3}=0.2488, P=0.6522$ ). Additionally, this effect of rearing environment remained significant when the density of BrdU-labeled cells in PZ 2 was corrected for body weight instead of zone volume (treatment effect, $F_{1,3}=15.0190$, $P=0.0304$; body wt effect, $F_{1,3}=1.7208, P=0.2809$; interaction $\mathrm{b} / \mathrm{w}$ treatment and body wt, $F_{1,3}=0.2655, P=0.6419$ ).

We found no difference between the simple and structurally complex rearing treatments in the number of proliferating cells in either PZ 1a (Fig. 3; treatment effect, $F_{1,3}=1.4653$, $P=0.3128$; PZ 1a volume effect, $F_{1,3}=13.2173, P=0.0359$; interaction $\mathrm{b} / \mathrm{w}$ treatment and $\mathrm{PZ} 1 \mathrm{a}$ volume, $F_{1,3}=1.6544$, $P=0.2886$ ) or in $\mathrm{PZ} 1 \mathrm{~b}$ (treatment effect, $F_{1,3}=1.1660$, $P=0.3593$; PZ 1a volume effect, $F_{1,3}=38.8805, P=0.0083$; interaction $\mathrm{b} / \mathrm{w}$ treatment and PZ 1a volume, $F_{1,3}=0.8844$, $P=0.4164)$. Similarly, the volume of proliferation zones 1a (treatment effect, $F_{1,3}=3.1839, P=0.1724$; body wt effect, $F_{1,3}=7.1006, P=0.0760$; interaction b/w treatment and body wt, $F_{1,3}=0.0537, P=0.8316$ ) and zone $1 \mathrm{~b}$ (treatment effect, $F_{1,3}=0.0517, P=0.8348$; body wt effect, $F_{1,3}=15.3641$, $P=0.0295$; interaction $\mathrm{b} / \mathrm{w}$ treatment and body $\mathrm{wt}$, $F_{1,3}=1.5180, P=0.3057$ ) did not differ between treatments.

\subsection{Structural enrichment did not alter telencephalon volume}

Fish reared in the simple environment $(N=6)$ were larger with respect to both body weight ( $t$ test, $d f=11, t=-2.632$, $P=0.0233)$ and standard length $(t=-2.361, d f=11$, $P=0.0378$ ) compared to fish reared in the structurally complex environment $(N=7)$. When body size was used as a covariate, we found no difference in telencephalon volume between treatments (Fig. 4; ANCOVA, treatment effect, $F_{1,9}=2.0799, P=0.1831$; body wt effect, $d f=1$, $F_{1,9}=6.0237, P=0.0365$; interaction $\mathrm{b} / \mathrm{w}$ treatment and body wt, $\left.F_{1,9}=0.2287, P=0.6439\right)$. Thus, growth of the telencephalon followed a similar trajectory in the two treatments, even though fish reared in the simple environment had a
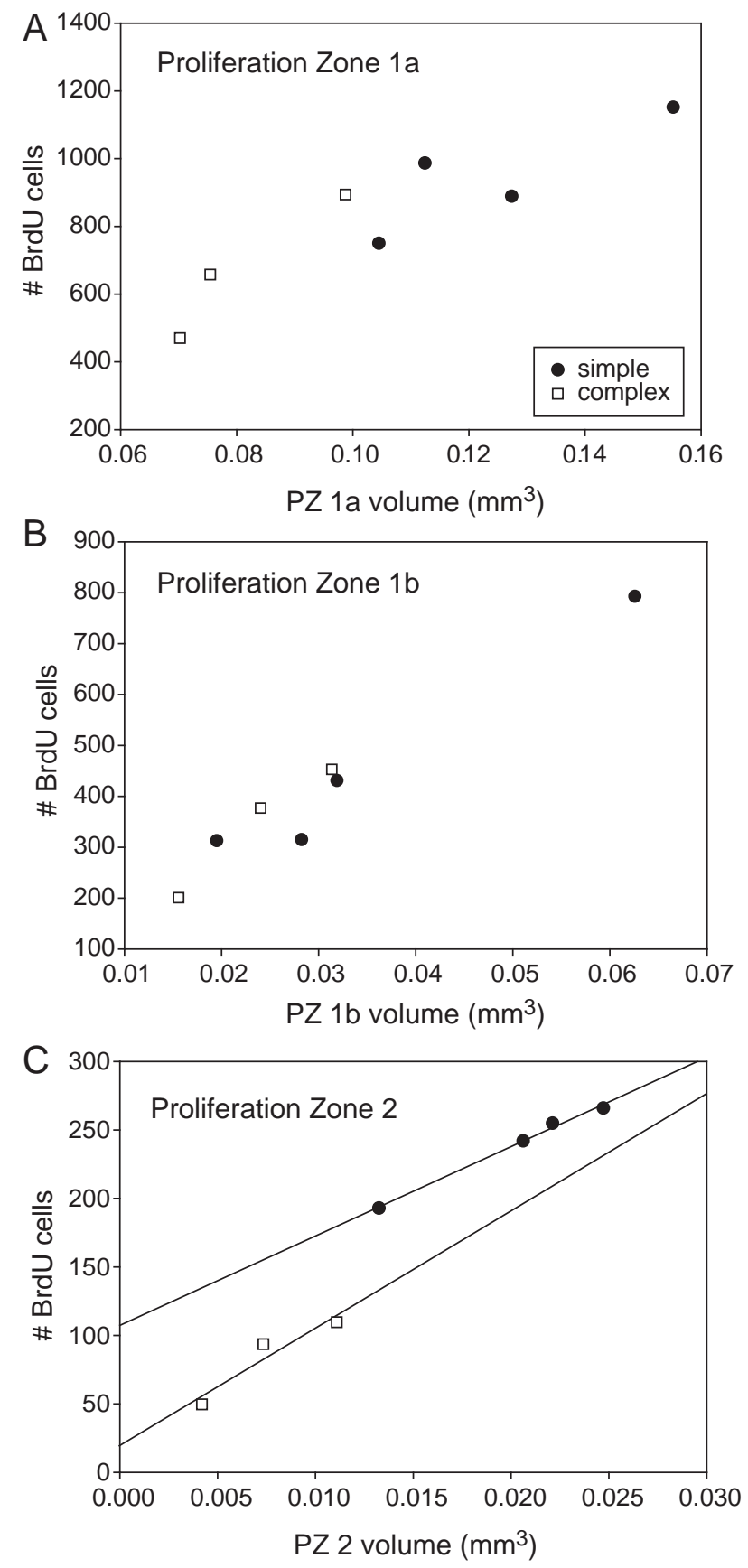

Fig. 3. Rearing environment altered the density of mitotic cells in proliferation zone 2. The number of BrdU-labeled cells is illustrated by treatment for proliferation zones $1 \mathrm{a}(\mathrm{A}), 1 \mathrm{~b}(\mathrm{~B})$, and 2 (C). Analysis showed a significant effect of rearing treatment on the number of BrdU cells in proliferation zone $2\left(F_{1,3}=15.4208, P=0.0294\right)$, but not in zones 1 a or 1 b. 


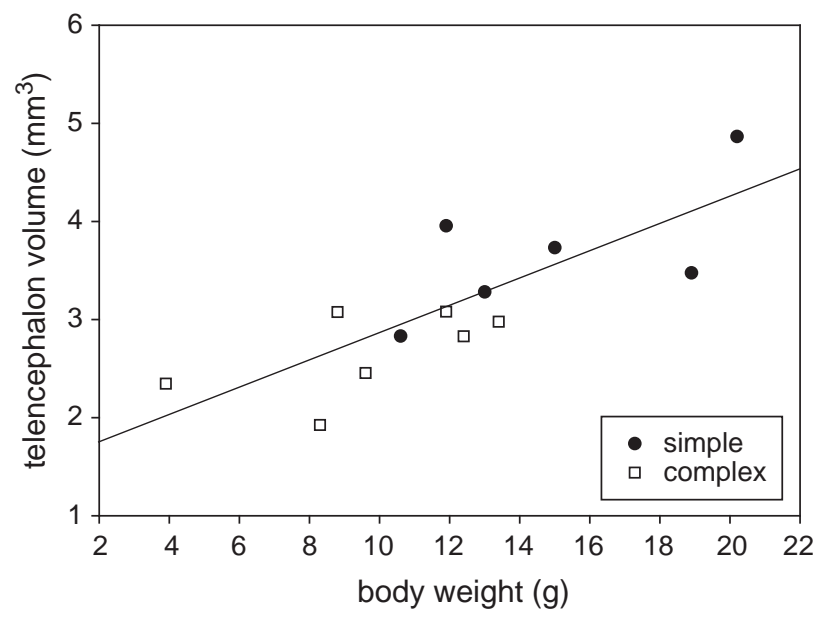

Fig. 4. Telencephalon size (volume, $\mathrm{mm}^{3}$ ) grew along the same trajectory in simple and structurally complex rearing treatments (ANCOVA, $\left.F_{1,9}=2.0799, P=0.1831\right)$.

larger telencephalon than fish reared in the structurally complex environment when not corrected for body size $(t$ test, $d f=11, t=-3.221, P=0.0081)$.

\section{Discussion}

While proliferation zones have been identified in the forebrain of other fishes (i.e., Ekström et al., 2001; Zikopoulos et al., 2000; Zupanc and Horschke, 1995), this is the first study to monitor both their growth rates and the influence of environment on their mitotic activity. Our data show that cell proliferation in the telencephalon of juvenile salmon is localized to three distinct areas - proliferation zones 1a, 1b, and 2. These zones correspond to areas of proliferation previously described in the forebrain of threespined stickleback (G. aculeatus; Ekström et al., 2001). Our results suggest that these zones grow at different rates, with zone 1a growing most rapidly at $6.29 \times 10^{-3} \mathrm{~mm}^{3}$ per $\mathrm{g}$ body wt, followed by zone $1 \mathrm{~b}$ at $3.50 \times 10^{-3} \mathrm{~mm}^{3}$ per g body wt, and zone 2 least rapidly at $1.34 \times 10^{-3} \mathrm{~mm}^{3}$ per g body wt.

Our data further show an environmentally-induced change in mitotic activity that is restricted to proliferation zone 2 , whereas proliferation rates in zones $1 \mathrm{a}$ and $1 \mathrm{~b}$ were not affected by rearing environment. This environmentallyinduced change in cell proliferation in zone 2 did not, however, translate into a change in telencephalon volume because the telencephalon in both treatments grew along the same trajectory. Newly born, BrdU-positive cells in proliferation zone 2 likely migrate from the ventricular edge inward to sites within the forebrain. While we do not know the phenotypic fate of cells produced by any of the proliferation zones (i.e., what percentage will die or differentiation into neuronal or glial cells), our results suggest that mitotic activity in these three zones may be regulated in different manners.
We found that salmon that experienced the simple environment for $\sim 4$ months showed a higher rate of mitotic activity in proliferation zone 2 than fish in the structurally complex environment. Why we saw an increase in proliferation rate in fish from the simple treatment is not clear, but may be related to differences in activity levels among treatments. The average flow velocity was faster in simple tanks, and spatial variation in flow velocity was also about twenty times greater (see Methods). Moreover, simple tanks had higher flow velocity around the tank edge with a lower velocity space in the middle of the tank. By contrast, structurally complex tanks had a more uniform, slower flow environment that also offered structural refuges for fish. Thus, altering structural complexity may have created a treatment difference in swimming activity. In mice and rats, increased physical activity associated with enrichment of the housing environment (i.e., adding a running wheel) has been shown to elevate neurogenesis in the hippocampus (van Praag et al., 1999; Brown et al., 2003a; Rhodes et al., 2003). It is thus possible that the difference in proliferation rate that we observed here might be associated with differences in swimming activity between treatments.

Enriched rearing can also alter glucocorticoids and other components of stress physiology in rats (Moncek et al., 2004) and mice (Marashi et al., 2003). For example, in rats, glucocorticoids have previously been shown to regulate neurogenesis (Gould et al., 1992), although these effects are dependent on the animal's previous social experiences (Mirescu et al., 2004). Such stress-induced changes in cell proliferation and neurogenesis may be relevant to the experiment presented here. Juvenile salmon in both treatments likely established social hierarchies. Yet, subordinates in simple tanks may have experienced greater social stress than their counterparts in structurally complex tanks, since hydrodynamic refuges (dead spaces) are not uniform and offer preferred feeding locations that can be dominated by a few individuals. On the other hand, structural features (i.e., cinder blocks) in the complex tanks may have created a more uniform distribution of food as well as refuges to escape aggression from dominants. In birds and mammals, social conditions have been shown to alter levels of cell proliferation in the brain (Fowler et al., 2002; Lipkind et al., 2002), and, although we did not document behavioral interactions as part of this preliminary study, it seems likely that differences in social conditions could have contributed to the treatment effects seen here. Further, variation in stress physiology has been recorded between hatchery-reared and wild-reared salmon (Poole et al., 2003), suggesting that such differences may be pertinent to changes in brain structures seen between fish from these environments (Marchetti and Nevitt, 2003; Kihslinger et al., 2003).

Still, attributing changes in neural proliferation and brain size to specific environmental (i.e., physical or social) factors has been difficult even in rodents, and work is just beginning to uncover the mechanisms by which environment can influence neurogenesis. Enriched rearing environ- 
ments have been shown to affect levels of neurotrophic factors in the brain, which might in part contribute to plastic changes in neurogenesis for animals reared in enriched environments (Falkenberg et al., 1992; Ickes et al., 2000). Variation in the complexity of the sensory environment has also been shown to affect patterns of immediate early gene expression throughout the brain (Pinaud, 2004). For example, rats exposed to enriched environments upregulate transcript and protein expression of nerve growth factor induced-A in neural tissues (Pinaud et al., 2002; Wallace et al., 1995). This elevation in immediate early gene expression suggests that animals living in enriched environments may experience enhanced sensory processing in their more complex environment, which might contribute to plastic reorganization of neural structures.

Alterations in rearing conditions are known to lead to changes in the behavior and life history of juvenile salmonids (Berejikian et al., 1996, 2000; Brown et al., 2003b; Mesick, 1988; see also Brown and Day, 2002), but whether these alterations are commonly associated with changes in neural development and function remains unknown. For instance, in a separate study that used the same two experimental treatments that we examined here, Watters (2003) found that these treatments influenced the timing of reproductive maturation in coho salmon (see also Watters et al., 2003). Yet clearly the rearing regimes used here were insufficient to significantly alter gross brain size. Rather, a complex synergy of environmental cues might be required to generate plastic changes in telencephalon volume of the magnitude that we have previously observed in juvenile salmon (Kihslinger et al., 2003). The developmental timing of exposure to these environmental cues may also be critical, as recent work looking at enrichment during the alevin stage of early life has shown that environment can alter brain size in steelhead trout (O. mykiss) (Kihslinger and Nevitt, 2003). Nevertheless, our results showing an environmentally-induced change in mitotic activity thus provide preliminary evidence to encourage detailed examinations of these questions in the future.

The environmentally-induced changes in cell proliferation seen here and the changes in brain size that we observed in other studies (Marchetti and Nevitt, 2003; Kihslinger et al., 2003) suggest that the conditions that fish experience as they develop in the wild could contribute to variation in brain phenotype (see also Lema and Nevitt, 2004b). This question is analogous to asking how environmental conditions affect behavioral and life history phenotypes (i.e., Nevitt and Dittman, 2004; Watters et al., 2003). In fish, variation in brain morphology in the wild is frequently associated with ecological differences between taxa (Eastman and Lannoo, 1995; Kotrschal et al., 1998; Kotrschal and Palzenberger, 1992; Huber and Rylander, 1992). For instance, the size of sensory areas in the brain (i.e., optic tectum, olfactory bulb) is associated with habitat type and diet in African cichlids (Huber et al., 1997). Similarly, a recent survey of brain size in deep sea fishes has shown that the size of brain regions associated with olfactory processing were larger in species found near the benthos, while brain regions involved in vision were larger in mesopelagic species (Wagner, 2002). Genetic differences within a species contribute to variation in brain size (Ishikawa et al., 1999), indicating that the size of brain structures in fish has a genetic basis and can evolve. But input from the environment may also interact with these genetic programs to generate intraspecific variation in neural growth and development. The extent and importance of such environmental effects on brain phenotype have not been formally addressed in fish. Our results suggest that the captive propagation and rearing of fish may provide a tractable model for studying how environmental conditions influence the development of neural phenotypes.

\section{Acknowledgements}

This research was supported by an NIH First Award (PHS DCO3174) to GAN. SCL received additional support from an NSF Graduate Research Fellowship. We thank the Iron Gate Hatchery for kindly providing fish, and Dr. Jason Watters for help constructing the treatment tanks. We are grateful to G. Cunningham, J. DeBose, R. Kihslinger and two anonymous reviewers, whose comments greatly improved the quality of this manuscript.

\section{References}

Bennett, E.L., Rosenzweig, M.R., Diamond, M.C., 1969. Rat brain: effects of environmental enrichment on wet and dry weights. Science 163, $825-826$.

Berejikian, B.A., Matthews, S.B., Quinn, T.P., 1996. Effects of hatchery and wild ancestry and rearing environments on the development of agonistic behavior in steelhead trout (Oncorhynchus mykiss) fry. Can. J. Fish. Aquat. Sci. 53, 2004-2014.

Berejikian, B.A., Tezak, E.P., Flagg, T.A., LaRae, A.L., Kummerow, E., Mahnken, C.V.W., 2000. Social dominance, growth, and habitat use of age-0 steelhead (Oncorhynchus mykiss) grown in enriched and conventional hatchery rearing environments. Can. J. Fish. Aquat. Sci. 57, 628-636.

Birse, S.C., Leonard, R.B., Coggeshall, R.E., 1980. Neuronal increase in various areas of the nervous system of the guppy, Lebistes. J. Comp. Neurol. 194, 291-301.

Brown, C., Day, R.L., 2002. The future of stock enhancements: lessons for hatchery practice from conservation biology. Fish Fish. 3, 79-94.

Brown, J., Cooper-Kuhn, C.M., Kempermann, G., Van Praag, H., Winkler, J., Gage, F.H., Kuhn, H.G., 2003a. Enriched environment and physical activity stimulate hippocampal but not olfactory bulb neurogenesis. Eur. J. Neurosci. 17, 2042-2046.

Brown, C., Davidson, T., Laland, K., 2003b. Environmental enrichment and prior experience of live prey improve foraging behaviour in hatcheryreared Atlantic salmon. J. Fish Biol. 63 (Suppl. A), 187-196.

Byrd, C.A., Brunjes, P.C., 2001. Neurogenesis in the olfactory bulb of adult zebrafish. Neuroscience 105, 793-801.

Eastman, J.T., Lannoo, M.J., 1995. Diversification of brain morphology in Antarctic notothenioid fishes: basic descriptions and ecological considerations. J. Morphol. 223, 47-83.

Ekström, P., Johnsson, C.-M., Ohlin, L.-M., 2001. Ventricular proliferation zones in the brain of an adult teleost fish and their relation to 
neuromeres and migration (secondary matrix) zones. J. Comp. Neurol. 436, $92-110$.

Falkenberg, T., Mohammed, A.K., Henriksson, B., Persson, H., Winbald, B., Lindefors, N., 1992. Increased expression of brain-derived neurotrophic factor mRNA in rat hippocampus is associated with improved spatial memory and enriched environment. Neurosci. Lett. 138, 153-156.

Fowler, C.D., Liu, Y., Ouimet, C., Wang, Z., 2002. The effects of social environment on adult neurogenesis in the female prairie vole. J. Neurobiol. 51, 115-128.

Gould, E., Cameron, H.A., Daniels, D.C., Woolley, C.S., McEwen, B.S., 1992. Adrenal hormones suppress cell division in the adult rat dentate gyrus. J. Neurosci. 12, 3642-3650.

Huber, R., Rylander, M.K., 1992. Brain morphology and turbidity preference in Notropis and related genera (Cyprinidae, Teleostei). Environ. Biol. Fishes 33, 153-165.

Huber, R., van Staaden, M.J., Kaufman, L.S., Liem, K.F., 1997. Microhabitat use, trophic patterns, and the evolution of brain structures in African cichlids. Brain Behav. Evol. 50, 167-182.

Ickes, B.R., Pham, T.M., Sanders, L.A., Albeck, D.S., Mohammed, A.H., Granholm, A-C., 2000. Long-term environmental enrichment leads to regional increases in neurotrophin levels in rat brain. Exp. Neurol. 164, 45-52.

Ishikawa, Y., Yoshimoto, M., Yamamoto, N., Ito, H., 1999. Different brain morphologies from different genotypes in a single teleost species, the medaka (Oryzias latipes). Brain Behav. Evol. 53, 2-9.

Kempermann, G., Kuhn, H.G., Gage, F.H., 1997. More hippocampal neurons in adult mice living in an enriched environment. Nature 386, 493-495.

Kihslinger, R.L., Nevitt, G.A., 2003. The early rearing environment produces variation in the size of brain subdivisions in steelhead trout (Oncorhynchus mykiss). Integr. Comp. Biol. 43, 944.

Kihslinger, R., Alvarado, A., Silverman, I., Lema, S., Marchetti, M., Swanson, P., Nevitt, G., 2003. Environmental rearing conditions produce differences in relative brain size in wild Chinook salmon Oncorhynchus tshawytscha. Program No. 561.7. 2003 Abstract Viewer/Itinerary Planner. Society for Neuroscience, Washington DC.

Kotrschal, K., Palzenberger, M., 1992. Neuroecology of cyprinids: comparative, quantitative histology reveals diverse brain patterns. Environ. Biol. Fishes 33, 135-152.

Kotrschal, K., Van Staaden, M.J., Huber, R., 1998. Fish brains: evolution and environmental relationships. Rev. Fish Biol. Fish. 8, 373-408.

Lema, S.C., Nevitt, G.A., 2004a. Evidence that thyroid hormone induces olfactory cellular proliferation in salmon during a sensitive period for imprinting. J. Exp. Biol. 207, 3317-3327.

Lema, S.C., Nevitt, G.A., 2004b. Variation in vasotocin immunoreactivity in the brain of recently isolated populations of a Death Valley pupfish, Cyprinodon nevadensis. Gen. Comp. Endocrinol. 135, 300-309.

Lipkind, D., Nottebohm, F., Rado, R., Barnea, A., 2002. Social change affects the survival of new neurons in the forebrain of adult songbirds. Behav. Brain Res. 133, 31-43.

Marashi, V., Barnekow, A., Ossendorf, E., Sachser, N., 2003. Effects of different forms of environmental enrichment on behavioral, endocrinological, and immunological parameters in male mice. Horm. Behav. 43, $281-292$.

Marchetti, M.P., Nevitt, G.A., 2003. Effects of hatchery rearing on brain structures of rainbow trout, Oncorhynchus mykiss. Environ. Biol. Fishes 66, 9-14.

Mesick, C.F., 1988. Effects of food and cover on numbers of Apache and brown trout establishing residence in artificial stream channels. Trans. Am. Fish. Soc. 117, 421-431.

Mirescu, C., Peters, J.D., Gould, E., 2004. Early life experience alters response of adult neurogenesis to stress. Nat. Neurosci. 7, 841-846.

Mohammed, A.H., Zhu, S.W., Darmopil, S., Hjerling-Leffler, J., Ernfors, P., Winblad, B., Diamond, M.C., Eriksson, P.S., Bogdanovic, N., 2002. Environmental enrichment and the brain. Prog. Brain Res. 138, $109-133$.
Moncek, F., Duncko, R., Johansson, B.B., Jezova, D., 2004. Effect of environmental enrichment on stress related systems in rats. J. Neuroendocrinol. 16, 423-431.

Mueller, T., Wullimann, M.F., 2002. BrdU-, neuroD (nrd)- and Hu-studies reveal unusual non-ventricular neurogenesis in the postembryonic zebrafish forebrain. Mech. Dev. 117, 123-135.

Nevitt, G.A., Dittman, A.H., 2004. Olfactory imprinting in salmon: new models and approaches. In: von der Emde, G., Mogdans, J., Kapoor, B.G. (Eds.), The Senses of Fishes: Adaptations for the Reception of Natural Stimuli. Narosa Publishing House, New Delhi, India, pp. 109-127.

Northcutt, R.G., Davis, R.E., 1983. Telencephalic organization in rayfinned fishes. In: Davis, R.E., Northcutt, R.G. (Eds.), Fish Neurobiology, Higher Brain Areas and Functions, vol. 2. Univ. of Michigan Press, Ann Arbor, pp. 203-236.

Pinaud, R., 2004. Experience-dependent immediate early gene expression in the adult central nervous system: evidence from enriched-environment studies. Int. J. Neurosci. 114, 321-333.

Pinaud, R., Tremere, L.A., Penner, M.R., Hess, F.F., Robertson, H.A., Currie, R.W., 2002. Complexity of sensory environment drives the expression of candidate-plasticity gene, nerve growth factor induced-A. Neuroscience 112, 573-582.

Poole, W.R., Nolan, D.T., Wevers, T., Dillane, M., Cotter, D., Tully, O., 2003. An ecophysiological comparison of wild and hatchery-reared Atlantic salmon (Salmo salar L.) smolts from the Burrishoole system, western Ireland. Aquaculture 222, 301-314

Rhodes, J.S., van Praag, H., Jeffrey, S., Girard, I., Mitchell, G.S., Garland Jr., T., Gage, F.H., 2003. Exercise increases hippocampal neurogenesis to high levels but does not improve spatial learning in mice bred for increased voluntary wheel running. Behav. Neurosci. 117, $1006-1016$

Rosen, G.D., Harry, J.D., 1990. Brain volume estimation from serial section measurements: a comparison of methodologies. J. Neurosci. Methods $35,115-124$.

Rosenzweig, M.R., Bennett, E.L., 1969. Effects of differential environments on brain weights and enzyme activities in gerbils, rats, and mice. Dev. Psychobiol. 2, 87-95.

Stuermer, C.A.O., Bastmeyer, M., Bahr, M., Strobel, G., Paschke, K., 1992. Trying to understand axonal regeneration in the CNS of fish. J. Neurobiol. 23, 537-550.

Sullivan, S.A., Barthel, L.K., Largent, B.L., Raymond, P.A., 1997. A goldfish Notch-3 homologue is expressed in neurogenic regions of embryonic, adult, and regenerating brain and retina. Dev. Genet. 20, $208-223$.

Uylings, H.B.M., van Eden, C.G., Hofman, M.A., 1986. Morphometry of size/volume variables and comparison of their bivariate relations in the nervous system under different conditions. J. Neurosci. Methods 18, 19-37.

van Praag, H., Kempermann, G., Gage, F.H., 1999. Running increases cell proliferation and neurogenesis in the adult mouse dentate gyrus. Nature Neurosci. 2, 266-270.

van Praag, H., Kempermann, G., Gage, F.H., 2000. Neural consequences of environmental enrichment. Nat. Rev., Neurosci. 1, 191-198.

Wagner, H.-J., 2002. Sensory brain areas in three families of deep-sea fish (slickheads, eels and grenadiers): comparison of mesopelagic and demersal species. Mar. Biol. 141, 807-817.

Wallace, C.S., Withers, G.S., Weiler, I.J., George, J.M., Clayton, D.F., Greenough, W.T., 1995. Correspondence between sites of NGFI-A induction and sites of morphological plasticity following exposure to environmental complexity. Mol. Brain Res. 32, 211-220.

Walsh, R.N., Budtz-Olsen, O.E., Torok, A., Cummins, R.A., 1971. Environmentally induced changes in the dimensions of the rat cerebrum. Dev. Psychobiol. 4, 115-122.

Walsh, R.N., Cummins, R.A., Budtz-Olsen, O.E., 1973. Environmentally induced changes in the dimensions of the rat cerebrum: a replication and extension. Dev. Psychobiol. 6, 3-7. 
Watters, J.V., 2003. Cost avoidance in mating systems: theory and lessons from coho salmon (Oncorhynchus kisutch). Ph.D. Dissertation, Univ. of California, Davis, 108 pp.

Watters, J.V., Lema, S.C., Nevitt, G.A., 2003. Phenotype management: a new approach to habitat restoration. Biol. Conserv. 112, 435-445.

Zar, J.H., 1996. Biostatistical Analysis, 3rd ed. Prentice Hall, NJ.

Zikopoulos, B., Kentouri, M., Dermon, C.R., 2000. Proliferation zones in the adult brain of a sequential hermaphrodite teleost species (Sparus aurata). Brain Behav. Evol. 56, 310-322.
Zupanc, G.K.H., 2001a. A comparative approach towards the understanding of adult neurogenesis. Brain Behav. Evol. 58, 246-249. Zupanc, G.K.H., 2001b. Adult neurogenesis and neural regeneration in the central nervous system of teleost fish. Brain Behav. Evol. 58, $250-275$.

Zupanc, G.K.H., Horschke, I., 1995. Proliferation zones in the brain of adult gymnotiform fish: a quantitative mapping study. J. Comp. Neurol. $353,213-233$. 